\title{
Same Coin-Different Sides? Futility and Patient Refusal of Treatment.
}

\author{
By Eleanor Milligan ${ }^{1}$
}

\section{Introduction}

The concept of futility in clinical care is contested with no universally accepted definition (Helft et al 2000), but with common threads running through the literature. Originating from the latin term 'futilus' meaning 'leaky', futility is defined in general terms as something which is "incapable of producing any useful result; pointless' 2. Applying this concept to clinical care, Schneiderman, Jecker, and Jonsen (1990) proposed that futile actions could be best defined as those that "cannot achieve the goals of the action, no matter how often repeated... or where the expectation of success is so unlikely, that the exact probability is often incalculable". They further proposed this could include "treatment that fails to benefit the person, even if it contributes to the functioning of the organism" (Schneiderman et al, 1990). Generally the literature has focussed on the clinician's view point about what constitutes futility and how to manage the responses clinically, ethically or economically.

This paper draws on the life experience of one young man. It considers whether re-framing this clinical encounter through the lens of 'futility', in contrast to the more conventional view of 'refusal of treatment', can promote greater shared understanding between patients and doctors as they negotiate the meaning of 'care' in these difficult circumstances.

\section{Case}

Jonas was 19 years old when he walked into hospital to have the abscess that was growing at the top of his spinal cord removed. It would be a delicate and dangerous operation. There was a slim chance that the consequences could be catastrophic. He had a choice though; he could choose not to have the operation and accept the potentially disastrous outcomes of that option. On balance, the 'least worst' option of surgery was taken.

But rare catastrophes do strike...

Regaining consciousness, he found himself attached to a ventilator, unable to move any part of his body. Luckily... his mind and ability to communicate remained intact.

As the monotonous months of 'rehabilitation' passed with no recovery in sight, his spirits flagged. Losing interest, when the nurses came to clean his tracheotomy tube as they often did, he began to refuse. 'Get fucked' he would tell them. Occasionally, he manoeuvred his mouth operated wheelchair away from his ventilator causing it to detach with

\footnotetext{
${ }^{1}$ I wish to acknowledge Dr Sarah Winch, Ms Alison New and Mr Peter Hamilton for their contribution and feedback in the development of this paper.

${ }^{2}$ Oxford English Dictionary Online. http://www.oxforddictionaries.com
} 
alarming results. He watched the unfolding chaos with some bemusement (and no small amount of terror).

When he lay in his own stench of urine and faeces, refusing to be touched, it was his deliberate decision. Besides, what could they offer him now? Restoration? Motivation? No chance. Intubation and sanitation? Now that was a different story... unlimited support to wither slowly, but hygienically. Cleanliness seemed to mean a lot to them... they called it 'preserving his dignity', but to him each and every act of 'care' was simply another forced and futile encounter...an attempt to plaster a veneer of social order over the crumbling façade of the ruin. He was a ruin, an unfixable relic of his former self, and he knew it.

\section{Discussion}

Our first reaction to Jonas' story is likely to categorise it as one of refusal of treatment by a competent adult patient. The right of an informed person with capacity to voluntarily refuse treatment, even if their refusal is 'irrational' (from the health carers perspective), is well enshrined in medical ethics. Even when treatment is clinically appropriate, providing physical comfort or preventing infection as in this case, the patient's autonomous right to refuse would ultimately trump the clinician's desire to do good. In their desire to deliver clinically appropriate care in the absence of patient consent his carers could (falsely) deduce that in his depressed state, he lacked capacity....after all how could a truly competent person make such a poor and perplexing choice? In this case, however, while Jonas was depressed, he was also unmistakably coherent and competent.

He was not terminally ill with a progressive disease. Instead he was living with an acquired condition that would lead to his premature death. Life-sustaining measures in the meantime could preserve his existence, and if purely maintaining physiological function was the aim, such measures could not be considered futile. Yet through his actions and words Jonas had powerfully communicated that he was now living a life unacceptable to him. His (unachievable) goal of restoration and his health care team's competing (compromise) goal of preservation were irreconcilable. From his perspective, any further actions taken to preserve or prolong it were, therefore, futile.

If this case were to be considered in terms of 'futility' as opposed to 'refusal of treatment', would such 're-framing' hold any advantage clinically or ethically for the patient or the treating team?

Common assumptions inherent in discussions about futility in the medical literature, locate the physician, not the patient, as the arbiter of what is futile (Lofmark and Nilstun, 2002). Objective judgments of clinical utility are often privileged over the subjective experience of patients and their families (Truog, 2010). While deeming a treatment 'futile' gives clinicians moral permission to refuse 'excessive' demands from patients at end-of-life (Murphy, 2008), the privilege of making a judgment on futility (however defined) appears less likely to be extended to a patient who determines their own situation is futile, but where some clinical utility remains. Two recent Australian cases provide 
pertinent examples of the lengths to which some patients have been required to go to in order to have their competently made decisions to refuse intervention upheld. In both cases (Bright water Care Group (Inc) v Rossiter; and HLtd v J[2010 SASC 176), competent adult patients who wished to cease basic medical care were required to go to court to enforce their right to refuse nutrition and hydration. That such competently made requests end up in the adversarial court system illuminates a broader medico-legal culture in which deference to clinical utility appears to hold disproportionate weight.

If we accept Mohindra's (2007) claim that, "any declaration (of futility) made solely in relation to a defined medical intervention is inchoate", surely we must also accept that any declaration that an intervention is not futile, made solely in relation to a defined medical intervention is similarly inchoate. The temptation to privilege a purely biological view of success in such circumstances can widen the gap between patient and physician, rather than promoting shared understanding, acknowledgment of difference and a mutually acceptable way forward.

The ethical consequence for the patient in having their actions characterised as 'refusal of treatment', rather than recognised as 'futile' in the sense that it has no subjective worth to them, could be that their experience becomes subordinated to the sovereignty of clinical utility. While this outcome may be professionally more palatable for clinicians, enabling them to focus on the (more predictable) biological facts, it necessitates positioning the patient in a pejorative way as a 'refuser' of an obvious 'good'.

Considering the discussion above, futility and patient refusal of treatment could be considered as different sides of the same coin. On one side, the goal of clinical utility takes precedence, on the other the subjective life goals of the patient. However, both sides are essentially making a judgment about whether the actions undertaken can achieve a particular goal (Schneiderman et al 1990). In reframing this situation as one of futility, rather than refusal of treatment, unspoken assumptions about whose goals are privileged become uncomfortably clear. In positioning the patient as a 'refuser', his assessment of the unacceptability of his situation can be more readily subjugated to the narrow clinical outcome. In this instance, such ethical re-framing might enable greater understanding of this patient's predicament. Re-framing might also open a space to enable staff to think beyond their immediate expectations and reactions to his 'unreasonable' behaviour and their feelings of professional rejection, to re-consider.

\section{Conclusion}

Patients like Jonas can challenge unspoken assumptions about futility and refusal of treatment; exposing implicit expectations about who decides what for whom, and on whose terms. Patients can, should and often do, make their own determinations of whether treatment is futile. If the "main moral driving force of medicine is to do what is good for the patient" (Gillon, 1997), what remains is for clinicians and health care systems to support them in their informed assessment. Re-considering familiar concepts in new ways may open a window of professional reflection for the benefit of those concerned. 


\section{REFERENCES}

Brody, B.A., and A. Halevy. 1995. Is futility a futile concept? Journal of Medical Philosophy 5 20:123-44.

Gillon, R.1997. "Futility"- too ambiguous and pejorative a term? Journal of Medical Ethics 23:339-40.

Helft, P.R., M. Siegler, M, and J. Lantos. 2000. The rise and fall of the futility movement. New England Journal of Medicine. 343:293-296.

Löfmark, R. and T. Nilstun. 2002.Conditions and consequences of medical futility-from a literature review to a clinical model. Journal of Medical Ethics 28:115-119.

Mohrinda, K. 2007. Medical futility: a conceptual model. Journal of Medical Ethics. 33 71-75.

Murphy, B. 2008. What has happened to clinical leadership in futile care discussions? Medical Journal of Australia 188 (7):418-419.

Truog, R.D. Is It Always Wrong to Perform Futile CPR? New England Journal of Medicine 2010; 362:477-479.

Schneiderman, L.J., N.S. Jecker and A.R.Jonsen.1990. Medical futility: its meaning and ethical implications. Annals of Internal Medicine 112:949-54. 